A scarlatinal tonsillitis ensued, but no rash or extensive desquamation.

Chimpianzee $C$. \& (Chart 1).

January 4th, rgo3.- l loop agar eulture B. typhi abd. (Fisher). Blood : no reaction, $1: 2$.

January 8 th. - Blood reacts trace $\mathrm{I}: 30$

January isth-Blood reacts well $x$ : 30 .

The blood never reacted in higher dilution. This animal died rimonths later on February zoth, s9o4, of pneumonia.

$$
\text { JAN. 1903 }
$$

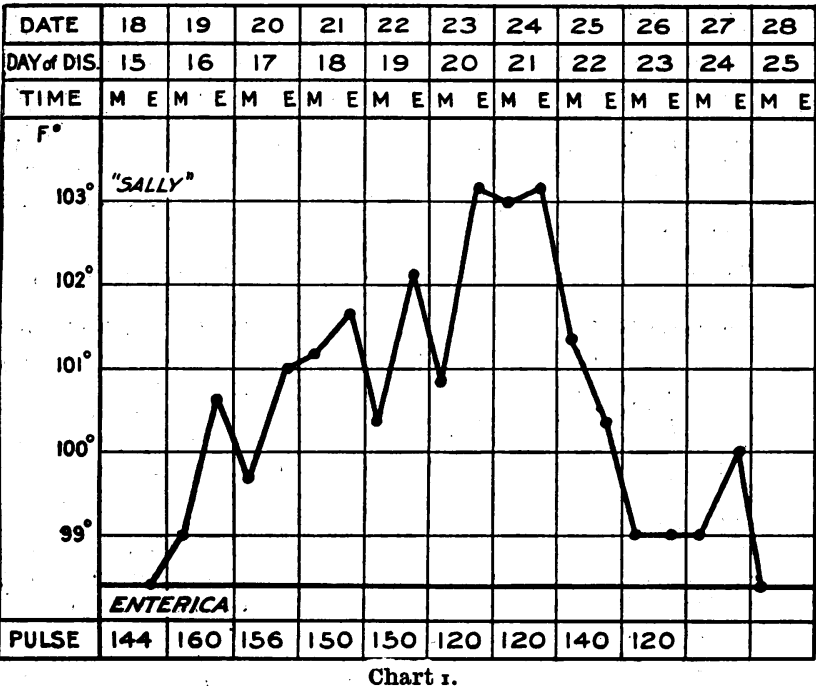

Chimpanzee $D$. $\$$

May 2rst, r903.-Portion of typhoid stool given in water. (B. typhi abd. could not be isolated.) Blood gave no reaction; nor did it at any time later.

June 4th.-Distended abdomen. Yellow stools.

June 8th.-Since there has been no rise of temperature some culture of B. typhi abd. is given in milk.

June z2nd.-The temperature curve has been quite erratic, and has come down to normal.

This animal was probably not infected. It died on August roth, rgo3, of diarrhoea, due to colitis-a common and fatal disease of the chimpanzee. From the faeces was isolated a bacillus closely resembling B. dysenterica Gray).

Chimpanzee. 우 (Chart 2.)

June 25 th, rgo2.-Clothed in nightgown from scarlet fever case. No result.

July 6 th. - Swab from case of scarlet ferer applied to throat.

July roth. Doubtful roseola.

JULY 1902

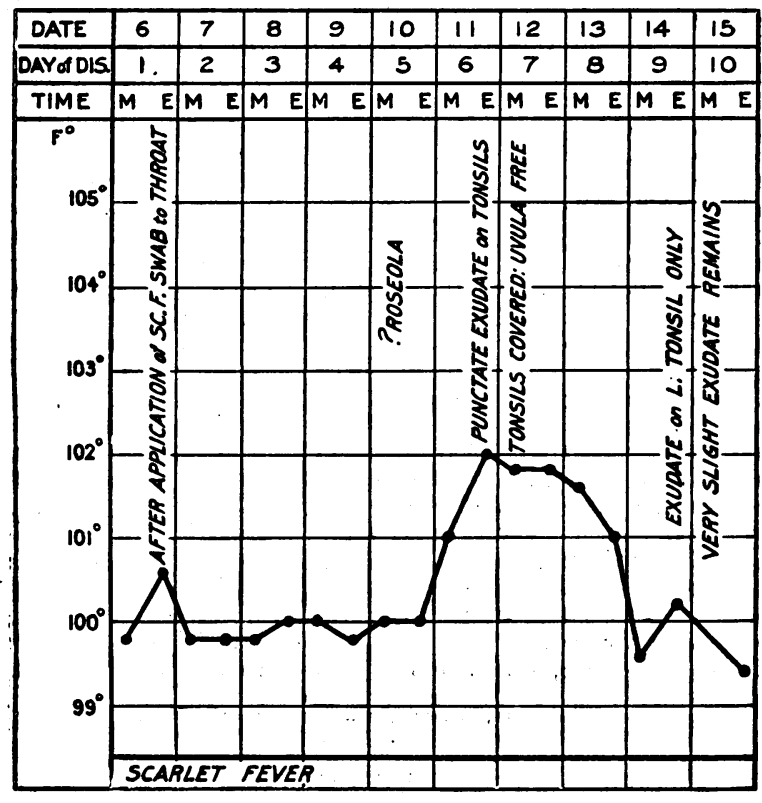

Chart 2.

July inth.-White specks on both tonsils; not on uvula.

July rath.-Exudate covers both tonsils. The roseola, mostly on abdo men, has not a scarlatiniform appearance.

July I4th. - Still exudate on leit tonsil only. (The temperature chart is given below.)

Streptococcus conglomeratus was isolated from the throat. Own blood agglutinates it.

Similar methods of infection were tried for measles and also the injection of blood taken direct from the median basilic view of measles cases. It had no effect: it may even have conferred immunity rather than conveyed infection.

Chimpanzee. $+?$

May 22nd, 1902.-Clothed in nightgown from case of measles. No effect.

June 5 th.-Swab from case of measles applied to nose and throat Temperature, $1002^{\circ} \mathrm{F}$

June 7 th.-Coryza. Temperature, $99.6^{\circ} \mathrm{F}$

June irth.-Slight roseola. Temperature, $102^{\circ} \mathrm{F}$

June $x_{5}$ th.-Rash gone. Temperature, $99.2^{\circ} \mathrm{F}$.

It remains doubtful whether this animal was realls infected with measles. Coryza is not uncommon in the chimpanzee, although here it seemed to have a causal relation to infection.

\title{
Chimpanzee. $\delta$
}

January 29 th, rgor.-Injected 2 c.cm. measles blood. No effect.

February 8th. -Injected 4 c.cm. measles blood. No effect.

February 22nd.-Clothed in measles nightgown. No effect.

Of these experiments I think that those on enterica assist in fulfilling Koch's third postulate as applied to Eberth's bacillus.

I have called these remarks a preliminary communication to indicate my sense of their incompleteness; but anthropoids are scanty and costly, so that the completion of the investigation may be a matter of years.

It only remains for me to acknowledge $\mathbf{m y}$ indebtedness to the British Medical Association and 'to the Grocers' Company, who to a large extent made the investigation financially possible, and to thank many friends and colleagues who, often at much trouble and inconvenience to themselves, provided me with material (2I cases of scarlet fever and 25 cases of measles) and laboratory facilities.

REFERENCES.

1 Balthazard, Toxine et 'Antitoxine Typhiques, $\mathrm{p}$ 2. 'Remlinger, Ann. de l'Ins. Pasteur, r897, p. $829 .{ }^{8}$ De Boinville, Lancet, 1902, vol. ii, p. 359.

REPORE LXXXIX.

\section{EXPERIMENTAL NEPHRITIS FOLLOWED BY DECAPSULATION OF THE KIDNEY.}

\section{WALKER HALL, and \\ G. HERXHEIMER} M.D.

$$
\begin{gathered}
\text { Assistant Lecturer in Pathology, } \\
\text { The Victoria University of } \\
\text { Manchester; Honorary } \\
\text { Pathologist.to the } \\
\text { Salford Royal } \\
\text { Hospital. }
\end{gathered}
$$
M.D. :Prosector to the Stadtisches Wiesbaden,

WHEN Edebohls first suggested the decapsulation of the kidney as a reasonable method of treatment in chronic nephritis, he based his proposal upon the urinary and general improvements which followed the fixation of a movable kidney by the removal of its capsule. In one of his cases which died four months after decapsulation, he observed "enormously dilated and enlarged blood vessels which penetrated from the fatty capsule through the capsule proper into the kidney substance." This access of additional blood he considered would provide increased nutrition, stimulate an extensive regeneration of the secreting cells, and consequently produce a more efficient excrétion of waste products. Whether decapsulation yields better results than the simpler reni-puncture of Reginald Harrison, which has been so widely and successfully employed, is a question which the available clinical data have not yet satisfactorily answered. We must wait from two to five years before making any definite conclusions as to the value of this operation. Meanwhile, we may with advantage investigate the anatomical aspect of the procedure, and thus the present inquiry has for its main object the observation of the tissue changes which follow the decapsulation of kidneys in which nephritis has been induced.

Claude and Balthazard, and Albarran and Bernard already in 1902 published $\mathrm{k}$ hort notes on the changes following renal 
decapsulation in healthy rabbits, and Harold Johnson, during the progress of our experiments, communicated the results of similar experiments upon normal dogs. As our observations on normal animals agree in the main with these workers, we may here shortly dismiss this part of the subject by stating that when the capsule is removed from healthy kidneys it reforms early, and at the end of ten to twenty-one days is represented by a fibrous covering thicker than the original capsule. Johnson was unable to detect any vascular anastomoses between the cortical and perirenal vessels in dogs, Emerson observed vascular connexions with the adjacent organs, but not with the fatty tissue. In rabbits Claude and Balthazard, and Jaboulay state that a slightly increased vascularity may occur, while Emerson was unable to demonstrate such conditions in these animals. After decapsulation of the kidney in some thirty-five rabbits, we also have not observed, either by ordinary or by serial sections, any marked formation of new blood channels between the kidney and the adherent tissues.

After the preliminary experiments we directed our attention to the production of an acute degenerative nephritis and to subsequent decapsulation of the kidney in order to more nearly approach the conditions under which the operation has its practical application. Of the numerous irritants employed for the experimental production of nephritis, few, if any, incite exactly the tissue changes which result from those auto-intoxications and hetero-intoxications which affect the human kidney. The majority of the available bacterial toxins are somewhat variable in their action, and cantharides is open to the same objection. Metallic irritants offer more advantages than even vinylamine, with which Lindeman has recently produced glomerular and tubular changes, and of these lead, for instance, is known to act directly upon the cells of the convoluted tubules, producing a coagulated necrosis; as its action is slow we decided to use one of the more rapidly-acting chromates, and ultimately selected the neutral ammonium chromate. This substance has been previously employed by Burmeister ${ }^{1}$ in his work on the acute inflammations of the kidney.

From a number of experiments we found that a dose of 0.5 to $0.75 \mathrm{c.cm}$. of a 2.5 per cent. solution of neutral ammonium chromate injected into rabbits weighing 1,500 to 2,000 grams produced very intenseacute congestion, a coagulative or degenerative necrosis of the cells of the convoluted tubules, a large number of hyaline casts, and the appearance of albumen in the urine within twenty-four hours. Glomerular and interstitial changes other than congestion were at first, as well as later, distinctly absent ; but in those animals who survived for over twenty days small cell infiltrations were visible around the medium-sized blood vessels. The effects of the irritant varied in different animals. In some, 4 in 1,000 albumen (Esbach) appeared in the urine during the first twenty-four hours, and these as a rule died in convulsions or coma within three to ten days. In one animal there was even 8 in 1,000 albumen; in others the albumen was only $\frac{1}{2}$ to 2 in 1,000 , and this quantity was present at death or disappeared within sixteen to eighteen days, when the animal lived so long. The urine always contained hyaline casts.

The normal capsule of the kidney consists of two distinct layers of fibrous tissue - an inner, thin, dense, and reticular, closely connected with the connective tissue surrounding the cortical cells, and an outer, broad, lamellated, and of loose texture, in some places covered by peritoneum. Forty-eight hours after the injection of neutral ammonium chromate the capsule is swollen, its fibres are separated by oedematous fluid, and its capillaries are congested and dilated. As a rule nephritis was first induced and decapsulation performed three days later, but in a few cases the capsule was first removed and the neutral ammonium chromate injected three days afterwards. The results observed were practically the same in each set of cases.

The Operation.

Two different routes were followed in the operation; in one the peritoneal cavity was opened, the intestines retracted the kidney brought to the wound, and the capsule incised and removed; in the other an incision was made along the external edge of the erector spinae muscles, the fascia separated anteriorly from the muscle, and the kidney approached from behind. The latter method was more generally employed. The wounds healed rapidly, and suppuration was only observed in one animal whose kidney was injected with milk for another purpose. In all 55 experiment rabbits were used, and the operations were performed in
Germany.; 17 of the chromicized animals were decapsulated on both sides, and 8 on one side. The remainder were only injected with neutral ammonium chromate and used as controls.

When removing the capsule it was impossible to always detach both the layers. The outer layer peeled off quite easily, but the inner layer came away in fragments, and during its removal the underlying tissues were lacerated. Thus in the latter case haemorrhages were large and focal, and the capsular changes were delayed by the absorption and organization of the clot; in the former the haemorrhage was slight, the capsule showed early signs of new formation, and adhesions were frequent and extensive. Speaking generally, the formation of flbrous tissue was the same in both instances, any difference being due to the rate of progress only. The protocols and detailed reports of the operations and the clinical data will be elsewhere stated, and in a later paper we hope to record the regenerative changes which occurred in the renal tubules.

\section{Macroscopical Appearances of the Decapsulated} KIDNEYS.

After twenty-four hours there was little trace of the capsule, and small clots of blood were visible on the surface of the kidney. At the end of four days the kidney was covered by a thin, whitish film, whose density varied in different areas. In some instances the kidneys were adherent to the liver or adjacent tissues. The blood clots disappeared, and the filmy covering increased in opacity and in density, until at the end of ten days it was as thick as the normal capsule of the other non-decapsulated kidney or of those of the control animals. To the end of the experiments the capsule continued to increase in thickness, and to become closely adherent to the neighbouring structures.

Microscopical Appearances.

The first animal was killed at the end of twenty-four hours, and the following appearances noted: In places where the outer layer of the capsule is absent there is a thin layer of blood and exudation; where the inner layer is missing, many of the tubules are ruptured, and there is considerable haemorrhage. The convoluted tubules show necrosis in patches, many of them contain hyaline casts, and such are also present in the collecting and straight tubules of the medulla. The glomeruli are intensely hyperaemic, and all the blood vessels are engorged.

During the operative procedures hairs from the skin became sometimes attached to the decapsulated areas; and, although from a surgical standpoint the occurrence was regrettable, yet their position amongst the newly-formed tissue was at times helpful in defining the exact amount of jcapsule which had been removed.

After forty-eight hours the haemorrhagic areas, which as a rule extend into the cortex, are but slightly changed. At those places where the outer layer of the capsule is alone missing, adhesions are being formed and the right kidney is often attached loosely to the liver. Four days after the operation there are distinct evidences of newly formed fibrous tissue where the inner layer of the capsule persists, and the intracortical haemorrhages contain round cells and also cells resembling fibroblasts. Many of the tubules are necrotic, and between them there is an increase of cellular elements. The casts and hyperaemia remain as before. On the ninth day the necrosis is well marked and the casts are numerous, but the hyperaemia is less intense. The capsule is now much thicker than normal and consists of loose cellular fibrous tissue. Adhesions to the surrounding fat and muscles are frequent, but the capsule is forming under the adhesions. The haemorrhages have practically disappeared, and their seats are indicated by patches of connective tissue which are visible between the atróphied tubules. The kidneys of those animals killed on the tenth to the fourteenth days exhibit a progressive thickness of the newly formed outer layer. The position of the lacerated areas is now only distinguishable by the cellular tissue, and their surface is covered by a thin layer of fibrous tissue. The new capsule contains numerous small vessels, collections of round and fusiform cells and small pieces of hair surrounded by giant cells. The glomeruli are still hyperaemic, but the necrosis is not so marked and few casts are visible.

From the fourteenth to the twentieth day the most evident changes are those connected with the disappearance of the hyperaemia and of the casts and the regeneration of the renal cells. The capsule is irregular in extent and in thickness. 
Under the adhesions it is dense and thin; where the organ is free there are frequent nodules of fibrous tissue the intervening parts being composed of loose, vascular, and somewhat lamellated fibres, almost devoid of cell elements. 'Up to the twenty-eighth day the specimens examined show a practically normal renal cortex, save that the capsule is much thicker than normal, and the intertubular strands of cellular tissue are well defined.

In addition to the ordinary haematoxylin and rubin and orange, Weigert's iron haematoxylin and Van Gieson, the sections were stained for fibrin and elastin. The former did not yield any noteworthy results. By the latter the relations of the blood vessels were determined. It was apparent that when distinct adhesions occurred, small arteries and veins were present in the tissues immediately surrounding the kidney, but these were always separated from the cortex by the thick, newly-formed capsule. When serial sections were made, it was found that these vessels still maintained their extra-renal position. The only route by which the vessels could definitely pass into the cortex was along the strands of cellular tissue, but although the capsule covering those areas was less dense than elsewhere, blood vessels large enough to contain elastic tissue were not present. Neither was there any evidence to show that the capillaries which passed from the capsule into the cortex were more numerous than those which are normally present.

Post-operative Changes.

To these experimental observations we may append a description of the post-operative capsular changes which occurred in two human kidneys which we have had the fortune to examine.

In one which had been incised with the object of removing a calculus, and which came to the post.mortem table sixteen days later, we observed some capsular changes near the point of incision. The capsule had retracted. and in its place there was extensive cell infiltration, with but little formation of fibrous tissue. In neighbouring areas, where the fibrous investment had been partially removed, the capsule was thickened, and the newly-formed tissue was richly cellular.

In another we were able to examine the capsular changes two years after an operation for movable kidney. The posterior portion of the capsule had been: removed in order that the organ might become adherent and fixed to adjacent structures. The kidney was adherent to a narrow portion of the psoas muscle for about 4 in., and the muscle tibres were absent in the plane of adhesion, and atrophied on the side of it. The renal cortex was covered by a very thick capsule of connective tissue of a stronger and denser type than that of the normal capsule, and in some places it was distinctly puckered. Microscopically, the newly-formed capsule consisted of thick fibrous tissue containing a few nuclei, the underlying tubules were somewhat atrophic, and the interstitial tissue was slightly increased both in extent and in cellular constituents. These changes occurred, as a rule, in scattered areas. Some of the glomeruli were entirely hyaline. Deeper in the cortex collections of small cells were here and there visible, but otherwise both the cortex and medulla were normal.

We are now in a position to consider what renal decapsulation realiy means. It consists of the removal of a portion of the capsule, or of the entire capsule, with more or less laceration of the cortical tubules, of haemorrhage, and of the exposure of a "raw" absorptive surface. It has been shown by Emerson that while immersion of a kidney in a solution of potassium iodide before decapsulation does not develop the drug in the urine, after decapsulation a similar immersion leads to its early appearance in the urine, so that the removal of the capsule accelerates the absorption of any local toxins.

In eight to fourteen days after renal decapsulation in animals in which degenerative nephritis has been induced, the kidney is covered by a thick, strong connective tissue capsule, and the haemorrhages and marked necrosis are replaced by cellular tissue, which in some instances is connected with the capsule, and which persists after the nephritic changes have resolved. When the capsule is removed in the first instance, the normal passage of capillaries from the capsule into the superficial areas of the cortex, well shown during renal infarction, will be broken; and, if this is afterwards fully regained, it is all that may be expected. In addition, the laceration of the stellate veins will partially obstruct the return of blood to the intertubular vessels, and new anastomoses will behere necessary. Neither in the former nor in the latter instances have we observed any new formation of vessels, but Emerson found that in normal dogs vascular connexions were formed with the pancreas, liver, and intestines, but not with the surrounding fatty tissue, and that these vascular channels were associated with the production of connective tissue, apparently penetrating into the parenchyma from the new capsule, and so marked as to present the picture of a commencing interstitial nephritis. He also states that the renal substance was free from lesions except around the new blood channels. The latter, however, are only described as small capillaries, and the injection of coloured gelatine employed for the demonstration only reached the capillaries and smaller vessels of the liver, although the oozing from the cut surface of the adherent organ was not inconsiderable.

While we must clearly admit that artificial animal nephritis cannot be too closely eompared with nephritis in a human subject, yet we submit that the rhanges produced by metallic poisons are somewhat similar in each case, and the experiments provide at least some grounds for the probable occurrence of like processes in the human kidney.

We must of course for the moment only deal with the forms of degenerative nephritis, as it is yet impossible to induce an interstitial nephritis in animals. From the anatomic standpoint yielded by our experiments and those previously reported, decapsulation does not appear to offer any advantages. And if there exists no anatomical basis for the operation in acute degenerative nephritis, it is surely impossible that in chronic nephritis the capsular changes will be less marked. If indeed the changes are at all analogous, we should imagine that the laceration, the haemorrhage, and the new formation of the capsule would rather tend to accelerate the interstitial inflammation; while in the event of any concomitant arterio-sclerosis there would be no possibility, of much vascular anastomosis or even of a satisfactory replacement of the channels ruptured during the removal of the capsule.

But if there is no anatomical basis for the operation, there may be another explanation of the rapid flow of urine-the increased excretion of urea, the disappearance of the albumen and casts which have been observed to follow decapsulation. By some the results are ascribed to the relief of congestion, but in our experiments the intense hyperaemia persisted after the capsule had reformed. Pel, Jaboulay and others suggest that the improvement is due to the action upon the sympathetic ganglia, and that the decapsulation should be considered in the same light as those operations which, undertaken to remove a renal calculus, lessen the pain and imprnve the general condition of the patient, although no calculus is found.

If the latter be the correct explanation, the question naturally then arises as to the necessity for the entire denudation of the renal cortex. Would not reni-puncture, or one longitudinal and several transverse incisions, while avoiding the main anatomical disadvantages, afford a sufficient stimulus to the sympathetic centres? We cannot at present offer any experimental evidence upon this point. That it would provide a sounder anatomical basis is probable ; at all events, it would more locally limit the interstitial and capsular processes in kidneys the seat of chronic nephritis.

Guiteras has recently compiled the results of some 120 cases in which the diagnoses of chronic nephritis were fairly well established before decapsulation and their postoperative courses followed for some months. Regarding the results from their most favourable standpoint, 16 per cent. of the total number may be said to be "cured," 40 per cent. thought to be improved, 11 per cent. unimproved, and 33 per cent. followed by early death. Suker reports 15 cases of nephritis in which retinal changes had occurred and which were submitted to decapsulation; 14 died within the "two-year" period and the history of the remaining one was somewhat questionable.

The value of these statistics is, however, minimized by several considerations. First, the operation has been necessarily restricted to the latest stages of the disease, and has often been only performed as a last hope; secondly, the exact stages and extent of chronic nephritis do not permit of accurate diagnosis; thirdly, chronic nephritis is as a rule characterized by acute exacerbations and frequent remis- 
sions, its anatomical course is in the main a progressive one, and the remittent stages often occur under treatment other than that of decapsulation.

Of the above 33 per cent. mortality, 26 per cent. died from chronic interstitial nephritis; and of the remainder, in 25 per cent. death occurred from the so-called chronic parenchymatous nephritis, and in 75 per cent. "diffuse"(?) nephritis was assigned as the cause.

In acute nephritis, anuria, haematuria, puncture and decapsulation of the kidney is said to yield relief and to favourably affect the function of the other kidney. In these cases it is suggested that the improvement is due simply to the relief of tension.

From the standpoint of pathology we may not make an excursion into the field of surgery, and therefore we must not discuss the possibilities of the operation. We feel, however, that the purpose of the paper would not be served unless we mentioned that while many American and some French surgeons regard the procedure as one that has come to stay and as possessing much promise in the treatment of degenerative and interstitial nephritis, such operators as Israel, Nicolayson, and others have already abandoned the method in chronic conditions. It is, of course, a matter of common knowledge that the simpler reni-puncture relieves tension and promotes renal functions, so perhaps the description of the changes observed after decapsulation may give more prominence to the method of simple incision, may emphasize the probability of rapid local reparation when the temporary obstruction is removed, and may suggest the earlier surgical treatment of those post-febrile and acute renal manifestations, which, when unrelieved, often terminate fatally.

Since the completion of our experiments Boncz-Osmolowsky has published a paper on " the changes in the kidney after removal of its capsule." He used rabbits for his experiments, and found that six days after decapsulation the leucocytes and connective tissue were increased between the tubules and that the cells of the superficial tubules showed granular changes in the protoplasm. Twelve days after the operation the superficial tubules and glomeruli were slightly compressed by the connective tissue elements, and there was atrophy of renal cells. He did not observe any new formation of blood vessels in the reformed capsule.

[Some portions of this paper were communicated to the March meeting of the Manchester Medical Society.]

\section{REFERENCE.}

1 Virchow's Archiv, Bd. cxxxvii.

BIBLIOGRAPHY.

Claude and Balthazard, Effets de la Décapsulation du Rein, Comptes Rendiss de ta Societé de Biologie, 1902, p. 239. Albarran et Bernard, Régéneration de la Capsule du Rein apres Décapsulation de l'Organe, societé de Biologie, June 2rst, 1902, p. 756. H. A. Johnson, Results of Decapsulation of the Kidney, Annals of Surgery, r903, p. 592. B. Boncz-Osmolowsky, Die Veränderung der Nieren bei Entiernung ihrer Kapsel, Russky Wratch, 1903, No. 21, Minch.med. Woch, 1904, S. 2066. Jaboulay-Gayet et Bassam, Du Traitement Chirurgical des ephrites, Arch. Gen. de Med, I903, p. $_{\text {. }}^{2904 . ~ H . ~ E m e r s o n, ~ S t u d i e s ~ u p o n ~ t h e ~ C a p s u l e ~ o f ~ t h e ~ K i d n e y, ~}$ American Physicians, vol. xvili, p. r94. Cavaillon et Trillat, Du Traitement du Mal de Bright, Presse Med. 1904. January oth. G. Edebohls, the Treatment of Chronic Bright's Disease. Medical Record. Igor, December 21 st 1902, p. 651 . 1903, p. 476, etc. J. Ferguson, the Surgical Treatment of Nephritis. Journ. American Medical A8sociation, I903, No, r. R. Guiteras, ro Cases of Bright's Disease Treated by Decapsulation (with full Literature), New York Med: Journ., 1903, November 7th, p. 881. R. Harrison, the Treatment of Some) Forms of Albuminuria by Renl-puncture, Lancet, 186 January 4th, BRITISH MEDICAL JOURNAL, 1896, October 17th, p. 4I8. I. Israel, Uber den Einfluss der. Nierenspaltung aut akuto und chronisch Krankheitsprozesse des Nierenparenchyms, Mitten. aus den Grenz. d. Med. und Chirurg, 1899, Bd. v ; Nierenkolik, Nierenblutung, und Nephritis Deut. med. Woch., 1902, p. 145; Nierenkrankheiten, 1901, p. 389. Korteweg, Die Indikationen Den lone. der Med. und Chirurg,, 1901, Bd. viii, p. 596. R. Lepine, sur lopportunite d'une Intervention Chirurgicale dans la . Mitteil. ans dem Grenz. der Med. und Chirurg. 1902 vol. $x$, Nos. I and Médicales. Journ de Med. de Bordeaux, 1902, February gth. Pel, Mitteil. aus den Grenz. der Med. und Chirurg., Igor, vol. X. No. 2. W. H. Porter Rational or Dietetic Treatment of Bright's Disease contrasted with Surgical Intervention, Medical Record, r902, p. 483. Rovsing, Wann und wie mussen die chronischen Nephriten operirt werden?' Monats. $f$. Urologie, rgoz. Oscar Rumpler, Der gegenwärtige Stand der Lehre der chirurgischen Behandlung der Nierenentzundung, Dissertation, Strassburg roo. J. A. Schmitt, Surgical Treatment of Chronic Bright's Disease, Medical Record, r9o2, September rth. A. Pousson. De l'Intervention Chirnrgicale dans Certaines Néphrites Médicales-Quatr. Sessiontion l'Association Francaise d'Urologie, Paris, 1890. Monats. $f$. Urologie, roon, I stricker, The Ocular Complications of Bright's Disease, Journ. Amer. Med. A880c., IgO4, p. 514 . G. F. Suker, Decapsulation of the Kidney and Intraocular Complications, Journ. Amer. Med. A8soc., r904, vol. xlii, No. 9. Tyson, Medical Record, 1903, p. 629. Tyson and Frazier, A Case of Decapsu . lation of the Kidney for Chronic Parenchymatous Nephritis. Transactions of the As8ociation of Amer. Fhysicians, vol. xvili, 1903; Med. Record, vol. i, 1902, p. 917 ; New York Med.Journal, 1903, October soth.

\section{SOME FURTHER OBSERVATIONS ON THE LIFE- HISTORY OF FILARIA IMMITIS, LEIDY.*}

By THOS. L. BANCROFT, M.B.EDIN.

I communicated to the Royal Society of New South Wales in June, 190I, a paper entitled "Preliminary notes on the intermediary host of Filaria immitis, Leidy," since then I have had the opportunity of following up several points in the life-history of this parasite, which remained to be elucidated.

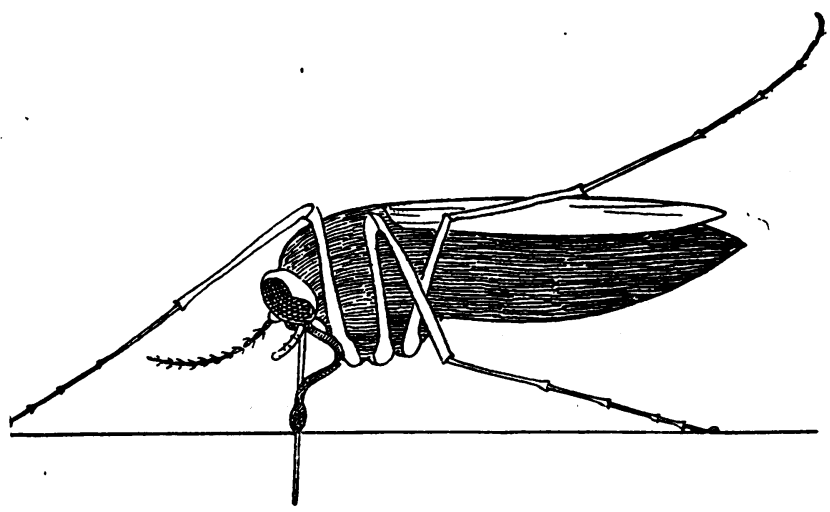

Fig. r.-Diagram of a "house mosquito" (Culex fatigans), Wied, in the act of imbibing blood, drawn from photomicrographs.

It was evident that the young or larval filariae, arrived at maximum development, as far as their life in the mosquito was concerned, passed out, in some way or other, into their final hosts, but the exact manner of exit was a disputed point. I had myself ${ }^{1}$ suggested that the worms passed down the proboscis into the wound inflicted by the mosquito; I did not think it possible for such helpless creatures to swim against the blood stream entering the mosquito's stomach by the epipharynx. Afterwards, ${ }^{2}$ whilst examining labia of filariated mosquitos, mounted in water and with a cover-glass, it was observed how readily the worms escaped from the apex of the proboscis or labium, and it was suggested that they naturally

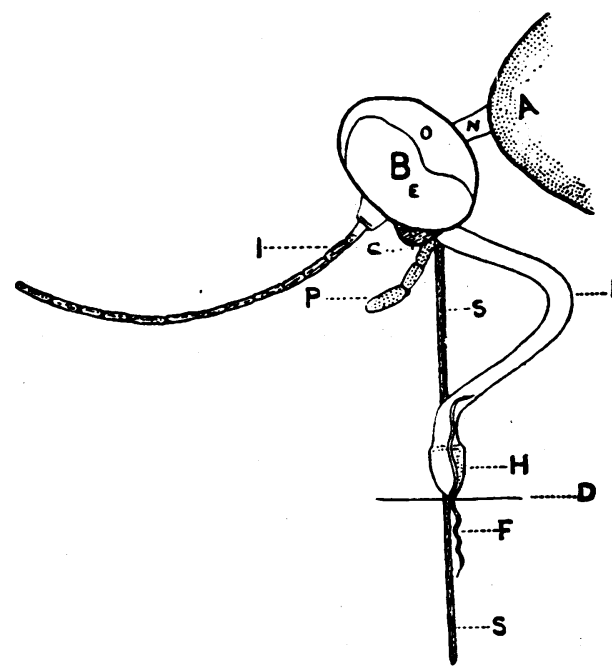

Fig. 2.-Diagram of the head of a mosquito imbibing blood, depicting the escape of a young filaria into C, clypeus ; $D$, skin ; $E$, eye ; $F$, filaria ; H, labellae ; I, antenna; L, labium; $N$, neck ; $\mathbf{O}$, occiput $\mathbf{P}$, palpi; B, stylets.

blood, the labium or sheath of the stylets is bent upon itself, whilst the stylets are thrust deep into the skin; Grass considered that when a labium containing filariae was thus buckled up it would be ruptured and the worms extruded. This hypothesis was easily disproved, for upon microscopic examination of the labia of filariated

* The expenses of this tinvestigation have been met in part by a grant of $£_{5}$ f from the British Medical Association, London, fuly 25 th, rgor. 